\title{
O USO DA SERRAGEM NO PROCESSO DE MINICOMPOSTAGEM
}

\section{THE USE OF SAWDUST IN A LITTLE COMPOUNDER SYSTEM}

\begin{abstract}
ELIANE SPRICIGO MARAGNO
Geóloga pela Universidade do Amazonas (UA). Química pela Universidade do Sul de Santa Catarina (Unisul). Pós-graduanda em Gestão de Recursos Naturais (lato senso) pela Universidade do Extremo Sul Catarinense (Unesc). Professora no ensino médio na Cidade de Criciúma-SC

\author{
DAIANE FABRIS TROMBIN \\ Graduanda em Ciências Biológicas (Bacharelado) pela Universidade do Extremo Sul Catarinense (Unesc)
}

\section{EDNILSON VIANA}

Biólogo pela Universidade Estadual Paulista (Unesp). Mestre em Ciências pela Universidade de São Paulo (USP). Doutor em Hidráulica e Saneamento pela Escola de Engenharia de São Carlos (USP). Professor/pesquisador no Programa de Pós-graduação em Ciências Ambientais/Mestrado (Unesc)
\end{abstract}

Recebido: 14/12/05 Aceito: 24/10/07

\section{RESUMO}

Neste trabalho utilizou-se quatro minicomposteiras de PVC cilíndricas e idênticas, $\mathrm{com} 40 \mathrm{~cm}$ de diâmetro, $75 \mathrm{~cm}$ de comprimento e com as extremidades abertas. Cada minicomposteira recebeu $35,5 \mathrm{~kg}$ de resíduos sólidos orgânicos, previamente triturados e $6 \mathrm{~kg}$ de serragem. Foi acompanhado o processo através de análises de $\mathrm{C} / \mathrm{N}$, variação da temperatura, grau de umidade e $\mathrm{pH}$. Os resultados mostraram que o uso do resíduo serragem como palhoso, nas minicomposteiras desenvolvidas, utilizando pequena quantidade de resíduos orgânicos, atingiu temperaturas de até $65^{\circ} \mathrm{C}$, permanecendo na faixa termofílica por aproximadamente 6 dias. Após 18 dias a massa em degradação atingiu a temperatura ambiente, sendo então, deixada para maturar por 55 dias. A umidade no sistema foi próxima de $60 \%$ no início e o $\mathrm{pH}$ final ficou na faixa de 8,0 a 8,5 . A relação $\mathrm{C} / \mathrm{N}$ inicial foi $30 / 1$ e chegou a 12/1 após 73 dias.

PALAVRAS-CHAVE: Compostagem; resíduo orgânico; serragem; minicomposteira; composto.

\section{INTRODUÇÃO}

Uma grande parcela das cidades brasileiras não possuem métodos de disposição adequados para os seus resíduos sólidos, depositando-os ainda em lixôes ou aterros controlados, os quais são fonte de expressiva degradação ambiental (IBGE, 2000). Neste cenário, os resíduos orgânicos constituem-se na principal fonte de impactos ambientais, pois produz o chorume na sua decomposição, que em contato com pilhas, baterias, medicamentos vencidos e outros componentes tóxicos, carreia uma grande quantidade de matéria orgânica, microrganismos, metais pesados e outros constituintes danosos para o meio ambiente.
Por outro lado, os resíduos sólidos orgânicos são materiais biodegradáveis, com um certo poder nutritivo (depende da forma e fonte geradora), podendo, portanto, serem utilizados para diversas finalidades como alimentação animal (Viana, 1999) e principalmente a compostagem (Diaz, 1999; Bidone, 2001).

A reciclagem dos resíduos orgânicos por meio do processo de compostagem tem se constituído no principal meio de retirada da grande quantidade destes resíduos do lixo municipal, uma vez que no Brasil este apresenta uma fração orgânica de aproximadamente 50\% (Philippi Junior, 1999; D'Almeida, 2000).

O processo de compostagem, por sua vez, prevê duas etapas distintas no seu desenvolvimento: a primeira de biodegradação do resíduo orgânico e a segunda de maturação, cura ou humificação do composto (Diaz, 1999; Jahnel, 1999; Budziak et al, 2004). Vários são os fatores que influem neste processo e muitos deles podem ser monitorados utilizando-se técnicas adequadas. Segundo Pereira Neto (1996), a umidade, oxigenação e temperatura, que são fatores essenciais na primeira fase, podem ser controlados revolvendo-se periodicamente a leira em compostagem.

O revolvimento do composto, ao mesmo tempo em que introduz novo ar, rico em oxigênio, libera o ar contido na leira, saturado de gás carbônico gerado pela respiração dos microorganismos. 
Essa renovação é importante, pois o teor de gás carbônico existente no interior da leira pode chegar a concentrações cem vezes maiores que o seu conteúdo normal no ar atmosférico. Faltando oxigênio na leira, haverá formação e acúmulo de dióxido de carbono e metano, componentes característicos da fermentação anaeróbia (Kiehl, 2002; Gpomez \& Ferrer, 2006).

Kiehl (1985), ressalta que o metabolismo dos microrganismos é exotérmico, e na fermentação aeróbia, principalmente, desenvolve-se um natural e rápido aquecimento da massa com a multiplicação da população microbiana, produzindo temperaturas acima de $70^{\circ} \mathrm{C}$.

As altas temperaturas no processo de compostagem são importantes pelo fato de eliminarem organismos patogênicos, os quais pouco resistem a temperaturas próximas de $50 \mathrm{a} 60^{\circ} \mathrm{C}$ por certo período de tempo. Estas temperaturas elevadas ocorrem em uma faixa denominada de termofílica, situadas entre $50-55^{\circ} \mathrm{C}$ e tendo como temperatura máxima $85^{\circ} \mathrm{C}$. As temperaturas que vão de $25-40^{\circ} \mathrm{C}$ encontram-se na faixa denominada de mesófila, podendo chegar ao máximo de $43^{\circ} \mathrm{C}$. Uma terceira faixa chamada criófila $($ crio $=$ frio), inicia-se quando a temperatura da composteira atinge a temperatura ambiente, coincidindo com a fase de maturação do composto (Kiehl, 1985).

Como a compostagem é um processo biológico de decomposição da matéria orgânica, a presença de água é imprescindível para as necessidades fisiológicas dos organismos, os quais não sobrevivem na sua ausência. Segundo Kiehl (2002), a umidade adequada deveria estar entre 40 e $60 \%$, sendo que $55 \%$ é considerada uma umidade ótima.

Tanto o excesso, quanto a falta de umidade dos resíduos em compostagem podem ser corrigidos por meio de revolvimentos. No segundo caso, repóe-se a água e/ou chorume aplicando-a com chuveiro fino. A adição de chorume fornece microrganismos que vão beneficiar o processo de compostagem (Marriel et al. 1987 apud Nunes, 2003).

$\mathrm{O}$ pH é tido como um parâmetro que afeta os sistemas de compostagem. A reação da matéria orgânica vegetal ou animal, é geralmente ácida. Iniciandose a decomposição, ocorre uma fase fitotóxica pela formação de ácidos orgâ- nicos que tornam o meio mais ácido do que o da própria matéria prima original. Entretanto, esses ácidos orgânicos e os traços de ácidos minerais que se formam, reagem com bases liberadas da matéria orgânica, gerando compostos de reação alcalina.

Com a compostagem há formação de ácidos húmicos que também reagem com os elementos químicos básicos, formando humatos alcalinos. Como conseqüência, o $\mathrm{pH}$ do composto se eleva à medida que o processo se desenvolve, passando pelo $\mathrm{pH} 7$ (neutro) e alcançando $\mathrm{pH}$ superior a 8 (básico), enquanto contiver nitrogênio amoniacal.

A relação $\mathrm{C} / \mathrm{N}$ é um fator importante que afeta a qualidade do composto e do processo de compostagem ( $\mathrm{Zhu}$, 2005). O equilíbrio da relação $\mathrm{C} / \mathrm{N}$ é um fator de importância fundamental na compostagem, já que, o principal objetivo do processo é criar condiçóes para fixar nutrientes, de modo a serem posteriormente utilizados como adubo.

Segundo Pereira Neto (1996), os microorganismos necessitam da presença de macro e micro nutrientes para o exercício de suas atividades metabólicas. Dentre os nutrientes utilizados pelos microrganismos, dois são de extrema importância, quais sejam: o carbono e o nitrogênio, cuja concentração e disponibilidade biológica de ambos afetam o desenvolvimento do processo.

O carbono é fonte básica de energia para as atividades vitais dos microrganismos e, na falta do nitrogênio não ocorre a reprodução celular dos mesmos. Em geral, os resíduos palhosos, como os vegetais secos, são fontes de carbono. Os legumes frescos e os resíduos fecais se caracterizam por serem fontes de nitrogênio. $\mathrm{O}$ excesso de carbono leva a um aumento do período de compostagem, neste caso, o nitrogênio necessário é obtido das células mortas dos microorganismos.

Kiehl (2002), Pereira Neto (1986) e Zhu (2005) descrevem que a relação $\mathrm{C} / \mathrm{N}$ inicial mais favorável para a compostagem fica em torno de 30/1. A relação $\mathrm{C} / \mathrm{N}$ é um parâmetro confiável para o acompanhamento da compostagem até se chegar ao produto acabado, humificado, no qual a relação ideal deve estar em torno de 12/1 (Kiehl, 2002; Pereira Neto, 1986).

Durante a compostagem, a degradação da matéria orgânica leva a uma redução do carbono orgânico. O nitrogênio total, ou seja, o nitrogênio orgânico, nítrico e amoniacal aumenta em virtude da mineralização. Conseqüentemente, ocorre diminuição da relação C/N (Kiehl, 1985).

Pereira Neto (1996), relata que durante a fase de maturação, há a continuidade da degradação, com a redução dos microorganismos patogênicos remanescentes e primordialmente a humificação dos intermediários mais estáveis. Os fungos e, principalmente os actinomicetos tornam-se o grupo dominante, dando continuidade à degradação de substâncias mais resistentes, como a celulose e a lignina. Nessa fase, ocorrerão complexas reaçóes enzimáticas, levando à produção de húmus por meio, principalmente, da condensação entre ligninas e proteínas.

Por outro lado, a utilização somente do resíduo orgânico ou somente de resíduo palhoso dificilmente será capaz de fornecer um balanceamento de nutrientes propício para o desenvolvimento do processo de compostagem, sendo portanto, recomendada a utilização de ambos, misturados em uma proporção ideal.

Os resíduos palhosos utilizados a fim de alcançar as características desejadas para o desenvolvimento do processo de compostagem, normalmente são denominados como materiais de enchimento ou fontes de carbono. Estes resíduos são adicionados com o intuito de ajustar a umidade, a relação carbono/nitrogênio ou a textura da massa em compostagem (Rynk,1992 apud Nunes, 2003).

Bhamidimarri \& Pandey (1996), apud Nunes (2003) classificam a serragem, um outro tipo de palhoso, como um resíduo ideal para ser utilizado como "agente de enchimento" na compostagem de dejetos de suínos, devido a sua característica de absorver umidade e fornecer porosidade adequada para o processo. É importante ressaltar que quando se trata do processo de compostagem, a capacidade de absorção de água é uma característica muito importante, pois permite regular o teor de umidade da massa de resíduos em degradação.

Embora a compostagem seja uma prática muito importante na retirada da grande parcela de resíduos orgânicos do lixo domiciliar, quando se trata do processo em grande escala, ela ainda é pouco adotada pelas municipalidades no Brasil (CEMPRE, 2005). 
A compostagem em pequena escala, por sua vez, por se tratar de dimensōes menores que o convencional, consegue atuar na própria fonte geradora (domicílios), não havendo necessidade de transporte até uma unidade de compostagem e possibilita aos membros residentes no domicílio que emprega a técnica, o cultivo de alimentos ou plantas medicinais/ornamentais a partir da produção de seu próprio composto. Por este motivo, a minicompostagem atua ainda como uma importante ferramenta de educação ambiental a medida em que o próprio gerador acompanha todas as fases de produção e uso do composto produzido pelos seus resíduos e por isso este processo tem grande potencial de disseminação junto a população, atuando como uma técnica complementar à compostagem em grande escala.

No processo de compostagem em pequena escala, o controle do alto teor de umidade dos resíduos é um fator imprescindível para o andamento adequado do processo. Neste caso, uma das alternativas é a adição de palhoso (restos de vegetais secos), que contribui para o equilíbrio da umidade e ainda auxilia na regulagem da relação $\mathrm{C} / \mathrm{N}$. Porém, nas cidades de médio e grande porte, um material em abundância e que poderia ser utilizada para tal finalidade é a serragem.

O uso da serragem, ao mesmo tempo em que permite absorver umidade da massa de resíduos orgânicos, apresenta características que poderiam evitar a compactação dessa massa, melhorando a aeração da mesma e com isso favorecendo o processo. Como ela é encontrada em abundância nas madeireiras, muitas vezes sem custo ou com baixo custo, o seu acesso pela população é favorecido, além do que representa uma opção de destino adequado para tais resíduos. Assim, conhecer o comportamento da serragem no processo de minicompostagem pode auxiliar ainda mais na disseminação deste processo junto aos domicílios.

Este trabalho tem como objetivo avaliar os efeitos da serragem, sobre os fatores que influenciam no processo de compostagem, utilizando tubos de policloreto de vinila como minicomposteiras.

\section{METODOLOGIA}

Foi desenvolvido no Núcleo de Pesquisa em Resíduos Sólidos (NRESOL), da Universidade do Extremo Sul Cata- rinense - UNESC, um sistema de minicompostagem cilíndrica em PVC, onde foi estudado neste projeto de pesquisa o uso da serragem como material palhoso. No estudo foram utilizadas quatro minicomposteiras (I, II, III e IV), com $40 \mathrm{~cm}$ de diâmetro e $75 \mathrm{~cm}$ de comprimento, com as extremidades vedadas com tela fina para evitar perda de resíduos e a presença de insetos no início do processo e permitindo ao mesmo tempo a aeração do sistema (Figura 1).

A serragem utilizada foi adquirida junto a uma madeireira da cidade de Criciúma-SC, proveniente de madeira não tratada, para evitar a presença de componentes químicos que pudessem interferir na atividade microbiana. A umidade da serragem foi determinada pelo método de Umidade a $65^{\circ} \mathrm{C}$, descrito por Lanarv (1988).

Os resíduos orgânicos utilizados foram coletados em residências do Bairro Universitário e em restaurantes da cidade de Criciúma num total de aproximadamente $150 \mathrm{~kg}$.

Antes de iniciar o experimento foram feitos testes preliminares para se obter a relação mais apropriada de resíduo orgânico/serragem, de modo a gerar menos chorume e assim regular o grau de umidade da massa em decomposição.

O teste foi realizado no NRESOL utilizando-se $47 \mathrm{~kg}$ de matéria orgânica triturada e $6 \mathrm{~kg}$ de serragem. Como a quantidade de chorume gerada foi elevada, acrescentou-se mais $2 \mathrm{~kg}$ de serragem. Baseando-se neste experimento chegou-se a relação ideal de resíduo orgânico/serragem que foi de 6:1. Assim, o percentual de mistura foi aproximadamente 6 partes de resíduo orgânico e 1 parte de serragem. Este conhecimento possibilitou colocar dentro de cada uma das 4 minicomposteiras $35,5 \mathrm{~kg}$ de resíduo orgânico triturado e $6 \mathrm{~kg}$ de serragem.

Após a coleta, os resíduos orgânicos foram homogeneizados e triturados em triturador marca Trapp.

Durante a etapa de degradação ativa, as minicomposteiras foram monitoradas e avaliadas, sendo anotados diariamente todas as características do composto, a freqüência de revolvimento, além das análises de temperatura, grau de umidade, $\mathrm{pH}$ e a relação $\mathrm{C} / \mathrm{N}$. $\mathrm{O}$ acompanhamento destes parâmetros é descrito detalhadamente a seguir.

\section{a) Revolvimento}

Como a quantidade de composto é pequena em relação aquelas descritas

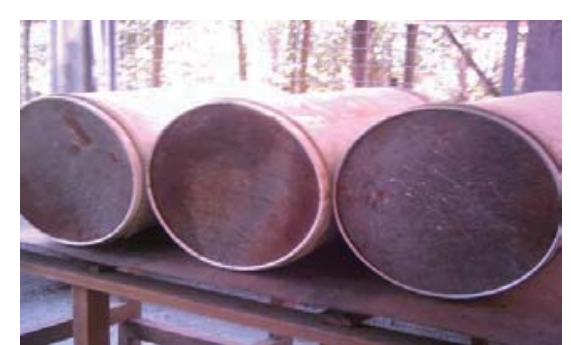

Figura I- Composteiras cilíndricas de PVC utilizadas no experimento

por Kiehl (2002) e Pereira Neto (1996), optou-se por revolvimentos manuais diários na fase de degradação ativa. Durante esta etapa foram observadas as características da massa em decomposição, adicionando-se água, se este apresentasse aspecto de "seco" e sem brilho. Esta umidificação era feita de forma bastante homogênea, com água e/ou chorume, utilizando para isto um regador.

\section{b) Temperatura}

A temperatura da massa de resíduos em compostagem foi realizada através de termômetro de mercúrio, com graduação de $1 \mathrm{a} 100^{\circ} \mathrm{C}$ e comprimento de $1,5 \mathrm{~m}$. Neste processo, inseria-se a haste do termômetro em vários pontos em cada composteira, considerando-se sempre a temperatura mais alta. Este procedimento foi repetido diariamente, ao longo da fase de degradação, no período vespertino, quando se verificava também a temperatura ambiente.

Quando a temperatura dentro das composteiras igualou-se à temperatura ambiente, considerou-se que havia iniciado a fase de maturação do composto.

\section{c) $\mathrm{pH}$}

O equipamento utilizado foi um pHmêtro marca Labmeter model pH 2. As análises eram realizadas diariamente nas 4 composteiras e o método utilizado consistiu em coletar uma amostra do composto e triturá-la. Então pesou-se $10 \mathrm{~g}$ da amostra triturada, adicionando-se $50 \mathrm{~mL}$ de água deionizada e em seguida, a mistura foi agitada por $5 \mathrm{mi}$ nutos, permanecendo em descansando por 30 minutos. Após este período a amostra foi agitada novamente por 5 minutos, quando se procedeu à leitura no pHmêtro.

\section{d) Umidade}

Foram feitos testes diários em todas as minicomposteiras utilizando o método Umidade a $65^{\circ} \mathrm{C}$, descrito por Lanarv (1988). Este método consiste 
em pesar uma amostra do composto (p), colocá-la em estufa a $65^{\circ} \mathrm{C}$ até a estabilização de peso $\left(\mathrm{p}_{1}\right)$ e calcular o teor de umidade através da fórmula:

$\mathrm{U}_{65^{\circ} \mathrm{C}}=\frac{100\left(\mathrm{p}-\mathrm{p}_{1}\right)}{\mathrm{p}_{-}}$

e) Cálculo da relação carbono/ nitrogênio

Durante a fase de degradação ativa foram feitas 3 análises para calcular o teor de matéria orgânica e o de nitrogênio total. As análises foram feitas pela Companhia Integrada de Desenvolvimento Agrícola de Santa Catarina - CIDASC. O teor de matéria orgânica possibilita calcular a porcentagem de carbono, e conseqüentemente a relação carbono/nitrogênio, conforme descrito por Lanarv (1988), da seguinte forma: $\% \mathrm{C}=$ teor de matéria orgânica

1,8

A primeira análise foi realizada no início da compostagem, onde foram coletadas amostras da serragem pura, de resíduo orgânico triturado puro e de resíduo orgânico misturado com a serragem na relação 6:1.

Após 15 dias do início da compostagem foram feitas duas análises de cada composteira, sendo uma amostra peneirada, a fim de separar a serragem, e a outra amostra não peneirada e encaminhadas para analise da matéria orgânica e nitrogênio total.

Ao término da fase de degradação ativa, ou seja, após 33 dias do início do experimento, foi feita a última análise desta fase, quando se coletou uma amostra peneirada de cada composteira.

Durante a fase de maturação o composto permaneceu acondicionado em caixas de papelão, levadas esporadicamente ao sol para evitar a umidade excessiva. As análises de $\mathrm{pH}$ e umidade feitas nesta fase não obedeceram a critérios de regularidade pré-estabelecidos.

No final do processo, ou seja, após 40 dias do início da fase de maturação, foi feita uma nova análise de matéria orgânica e nitrogênio total para o calculo da relação $\mathrm{C} / \mathrm{N}$.

\section{RESULTADOS E DISCUSSÃO}

Os resultados obtidos no processo de minicompostagem, utilizando como material palhoso a serragem, referem-se ao acompanhamento dos parâmetros temperatura, $\mathrm{pH}$, umidade e relação $\mathrm{C} / \mathrm{N}$. As análises de metais pesados e de qualidade do composto não foram realizadas porque o objetivo do trabalho se restringiu, em uma primeira etapa, em verificar o desenvolvimento do processo de compostagem em relação a temperatura, umidade, $\mathrm{pH}$ e relação $\mathrm{C} / \mathrm{N}$.

Durante o processo de compostagem também foram feitas observações visuais, como: presença de larvas, odores e textura do composto. O comportamento das quatro minicomposteiras foi muito semelhante e os parâmetros analisados são descritos a seguir para todas elas.

\section{Temperatura desenvolvida}

Analisando os resultados das quatro minicomposteiras percebe-se que a temperatura ambiente, à medida que oscilava, não exercia forte influência sobre o desenvolvimento do processo de compostagem nas minicomposteiras em estudo (Figura 2). Isto significa que o sistema não sofre prejuízo do ambiente mesmo em dias de inverno, quando as temperaturas são mais baixas, considerando a pequena quantidade de resíduos orgânicos utilizada. Observa-se também que as temperaturas desenvolvidas nas quatro minicomposteiras foram muito semelhantes desde o início até o final do processo.

As minicomposteiras iniciaram a fase termofílica por volta do quarto dia e permaneceram até o décimo dia, contabilizando seis dias nesta fase (Figura 2). Segundo Pereira Neto (1996) estas temperaturas são importantes para que ocorre a eliminação de microrganismos patogênicos.
Para este tipo de experimento, com pouca quantidade de resíduos, estabeleceu-se uma freqüência de revolvimento baseada especialmente no comportamento das temperaturas que eram desenvolvidas. Assim, o revolvimento foi praticamente diário na fase de degradação ativa, observando-se que o não revolvimento implicava na redução da temperatura.

\section{pH}

A Figura 3 mostra o comportamento do $\mathrm{pH}$ nas quatro minicomposteiras durante todo o experimento. De maneira geral o $\mathrm{pH}$ que iniciou em 4,5, tornou-se alcalino, atingindo $\mathrm{pH} 9,0$ no décimo dia e permanecendo neste patamar por seis a sete dias, quando então teve alguma redução, estabilizando entre 8,0 e 8,5 .

Pode-se dizer que o $\mathrm{pH}$ do experimento em questão comportou-se conforme relatado por Kiehl (2002). O autor explica que numa compostagem de grande escala o $\mathrm{pH}$ inicia-se ácido, tornando-se alcalino quando atinge índices próximos a 9,0. Ele permanece neste nível enquanto houver nitrogênio amoniacal, baixando um pouco em seguida, quando este passar para a forma de nitrato.

\section{Umidade}

A Figura 4 mostra o resultado das análises diárias de umidade feitas nas quatro minicomposteiras durante todo o período do experimento.

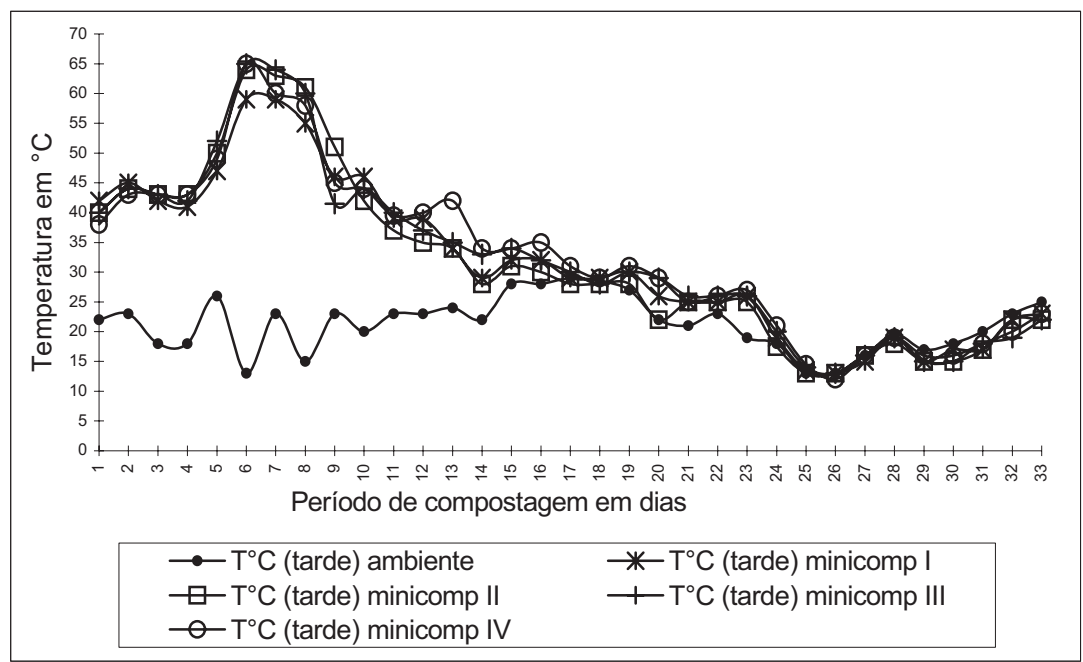

Figura 2 - Variação da temperatura (período vespertino) nas quatro minicomposteiras durante o processo de compostagem 
Observa-se na Figura 4 muitas oscilações na umidade em todas as minicompostagens, que podem ser atribuídas a vários fatores, dentre eles pode-se citar a temperatura desenvolvida durante o processo, que faz com que a massa de resíduos perca água por evaporação.

A partir do quinto e até por volta do oitavo dia, a umidade teve uma queda acentuada. Este período coincide com o da fase termofílica, quando as temperaturas ultrapassaram $45^{\circ} \mathrm{C}$. Durante este período houve intensa liberação de vapor de água, ressaltando porém, que neste mesmo período as minicomposteiras estavam sendo regadas com chorume e/ou água. As minicomposteiras foram regadas quase que diariamente até o décimo oitavo dia do experimento. De uma maneira geral, entre o décimo sétimo e décimo oitavo dia a umidade estabilizou em níveis próximos a $60 \%$, um nível bastante satisfatório, pois segundo Kiehl (2002) e Pereira Neto (1996) a umidade ideal é em torno de $55 \%$.

\section{Relação Carbono/ Nitrogênio}

Durante os setenta e três dias de experimento, foram feitas, devido ao elevado custo, apenas quatro análises $\mathrm{C} / \mathrm{N}$. A Tabela 1 permite visualizar a evolução da relação $\mathrm{C} / \mathrm{N}$ nas quatro análises feitas durante o processo de compostagem. Cabe salientar que os resultados da segunda, terceira e quarta análises referem-se as amostras peneiradas. $\mathrm{O}$ resultado descrito para o início do experimento ( $1^{a}$ análise) é o mesmo para todas as minicomposteiras, pois todas elas utilizaram o mesmo tipo de resíduo.

O resultado da primeira análise de resíduo orgânico com serragem, descrito na Tabela 1 , indica que a relação C/N obtida foi bastante satisfatória, pois, segundo Kiehl (2002) e Pereira Neto (1996) a relação ideal para uma rápida e eficiente compostagem é por volta de 30:1.

Observa-se que durante todo o processo a relação $\mathrm{C} / \mathrm{N}$ das quatro minicomposteiras diminuiu gradativamente até chegar ao estágio de maturação do composto, quando então esta relação ficou, após os setenta e três dias, em média $12 / 1$, estando dentro da faixa ideal, que é de 8 a 12/1. Este resultado indica um composto maturado, pronto para ser utilizado como fertilizante.

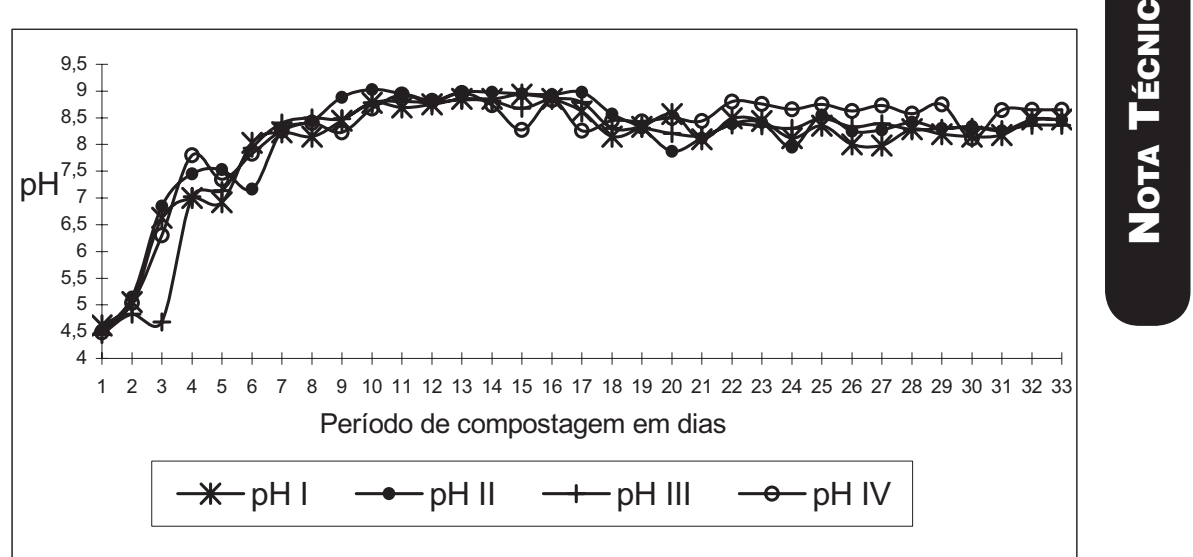

Figura 3 - Variação do pH nas quatro minicomposteiras durante o processo de compostagem

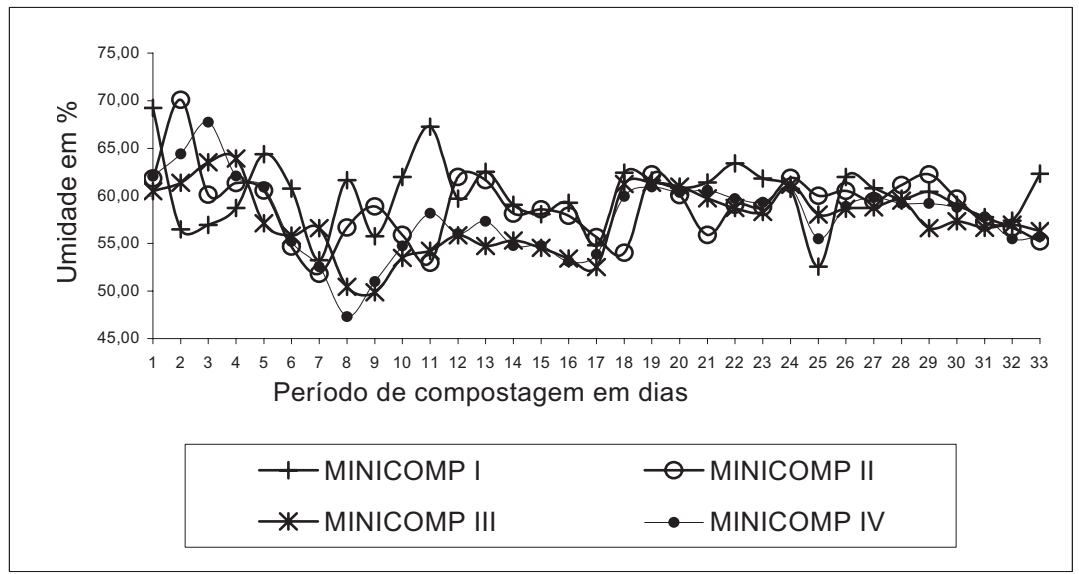

Figura 4 - Variação da umidade nas quatro minicomposteiras durante o processo de compostagem

Tabela I - Análises da relação C/N da massa de resíduos nas quatro minicomposteiras estudadas

\begin{tabular}{ccccc}
\hline Amostra & 1a Análise & 2a Análise & 3a Análise & 4a Análise \\
\hline Minicompodteira I & $30 / 1$ & $32,8 / 1$ & $22.9 / 1$ & $12,5 / 1$ \\
\hline Minicompodteira II & $30 / 1$ & $26.6 / 1$ & $25,7 / 1$ & $11,8 / 1$ \\
\hline Minicompodteira III & $30 / 1$ & $24,5 / 1$ & $24,8 / 1$ & $13,2 / 1$ \\
Minicompodteira IV & $30 / 1$ & $26,1 / 1$ & $23,3 / 1$ & $10,3 / 1$ \\
\hline
\end{tabular}

\section{Características do composto produzido}

$\mathrm{O}$ aspecto visual do composto maturado foi excelente, apresentando cor e odor característico de terra de mata.

O composto das minicomposteiras II, III e IV assemelharam-se muito quanto a textura. Cabe salientar que após terem sido peneirados, para retirar o excesso de serragem, o composto produzido, sem exceção, apresentaram-se muito semelhantes.

No início do experimento foram colocados em cada minicomposteira
$35,5 \mathrm{~kg}$ de resíduo orgânico triturado e $6 \mathrm{~kg}$ de serragem, totalizando $41,5 \mathrm{~kg}$ de resíduo, em cada minicomposteira. Após setenta e três dias o composto maturado de cada uma das minicomposteiras foi pesado, resultando na minicomposteira I, 7,68kg; na minicomposteira II, $7,92 \mathrm{~kg}$; na minicomposteira III, $7,14 \mathrm{~kg}$ e na minicomposteira IV, $6,98 \mathrm{~kg}$. Com este resultado pode-se afirmar que houve uma redução média de $34 \mathrm{~kg}$, ou seja, de $82 \%$ da massa de resíduos inicial neste tipo de processo em pequena escala e utilizando serragem. Salienta-se que a serragem em si 
encontra-se pouco degradada, motivo da grande redução observada.

\section{Observações visuais no processo de minicompostagem}

Houve pouco odor exalado pela massa de resíduos em compostagem. No décimo terceiro dia de experimento o resíduo começou a apresentar um leve cheiro de amônia, o qual permaneceu até por volta do trigésimo dia. A partir daí e até o final do experimento, o composto apresentou um cheiro muito bom de terra de mata.

A presença de fungos de cor esbranquiçada foi observada logo na primeira semana do experimento, permanecendo até por volta do vigésimo dia, quando então começaram a surgir ácaros, os quais permaneceram até o início da fase de maturação. O desaparecimento dos ácaros coincidiu com o período em que as minicomposteiras não estavam mais sendo regadas e sim expostas ao sol.

Durante a fase de maturação pôde-se observar novamente fungos esbranquiçados. Segundo Pereira Neto (1996), nesta fase os fungos e actinomicetos tornam-se o grupo dominante. $\mathrm{O}$ autor cita ainda que as colônias de actinomicetos são visíveis a olho nu através de sua cor esbranquiçada.

\section{CONCLUSÕES}

A serragem utilizada como palhoso no sistema de minicompostagem do NRESOL mostrou que é possível produzir um composto com excelente grau de maturação utilizando apenas $35,5 \mathrm{~kg}$ de resíduo orgânico e $6 \mathrm{~kg}$ de serragem. Além disso, utilizando pouca quantidade de resíduos orgânicos, em associação com a serragem, obteve-se temperaturas de até $65^{\circ} \mathrm{C}$, com permanência de seis dias na faixa termofílica, período importante para eliminação de microrganismos patogênicos.

A fase de degradação ativa do processo analisado foi curta e durou 6 dias. Por outro lado, a fase de resfriamento foi mais longa, levando 11 dias para atingir a temperatura ambiente. $\mathrm{O}$ período de maturação, por sua vez, durou 55 dias e o processo como um todo requereu 73 dias de compostagem.

Parâmetros como o pH e a umidade também apresentaram um comportamento satisfatório durante o desenvolvimento do processo de compostagem e a relação $\mathrm{C} / \mathrm{N}$ inicial foi de 30/1, que segundo Kiehl (2002) e Pereira Neto (1996), é extremamente favorável para uma rápida e eficiente compostagem. A relação $\mathrm{C} / \mathrm{N}$ final do composto obtida foi em média $12 / 1$, indicando desta forma que o composto estava maturado e já podia ser utilizado como fertilizante.

Para este tipo de experimento, com pouca quantidade de resíduo e utilizando serragem, estabeleceu-se uma freqüência de revolvimentos baseada especialmente no comportamento das temperaturas que eram desenvolvidas. Assim, o revolvimento foi praticamente diário, na fase de degradação ativa, observando-se que o não revolvimento implicava na redução da temperatura.

O uso de serragem na minicompostagem, ao mesmo tempo em que gerou pouco composto no final do processo, ou seja, redução de $82 \%$, também criou uma condição importante para sistemas de minicompostagem a partir do momento em que ela não degrada rapidamente, restando no final da compostagem um palhoso próprio para ser utilizado novamente em outras compostagens. Neste contexto é necessário considerar que a minicompostagem é uma importante alternativa para muitos domicílios e requer um palhoso adequado e pratico para o bom andamento do processo.

\section{AGRADECIMENTOS}

Os autores agradecem ao Conselho Nacional de Desenvolvimento Científico e Tecnológico (CNPq) e a Universidade do Extremo Sul Catarinense (UNESC) pelo apoio financeiro.

\section{REFERÊNCIAS}

BIDONE, F. R. A. Resíduos sólidos provenientes de coletas especiais: eliminação e valorização. $1 \mathrm{ed}$. São Paulo: PROSAB, 51 p. 2001.

BUDZIAK, C. R.; MAIA, C. M. B. F.; MANGRICH., A. S. Transformaçôes químicas da matéria orgânica durante a compostagem de resíduos da indústria madeireira. Química Nova, vol.27, $\mathrm{n}^{\circ} .3, \mathrm{p} .399-403.2004$

CEMPRE - Compromisso Empresarial para a Reciclagem. Site: www.cempre.org.br, acesso em: 23/11/2005.

D'ALMEIDA, M. L. O, VILHENA, A. Lixo municipal: manual de gerenciamento integrado. 2. ed. São Paulo : IPT/CEMPRE, 370p. 2000.

DIAZ, L. F. Book review: The Science of Composting By Eliot Epstein Laricaster,
Technomic Publishing Co. Waste Management \& Research, vol.17, no. 2, p.66. 1999.

GÓMEZ, R.B.; FERRER, A.S. The use of respiration indices in the composting process: a review. Waste Management \& Research, vol. 24, no1, p. 37-47. 2006.

INSTITUTO BRASILEIRO DE GEOGRAFIA E ESTATÍSTICA (IBGE). Pesquisa Nacional de saneamento Básico 2000. Disponível em: www. ibge.gov.br. Acesso em 12/11/2004.

JAHNEL, M. C.; MELLONI, R.; CARDOSO, E. J. B. N. Maturidade de composto de lixo urbano. Scentia agricola., 1999, vol.56, n² 2, p.301-304. 1999.

KIEHL, J. E. Fertilizantes Orgânicos. 1 ed. Piracicaba: Editora Agronômica Ceres Ltda, 492p. 1985.

Manual de compostagem: Maturação e Qualidade do composto. 3 ed. Piracicaba: edição do autor, 171p. 2002.

LANARV, LABORATÓRIO NACIONAL DE REFERÊNCIA VEGETAL. Análise de Corretivos, fertilizantes e Inoculantes. Métodos Oficiais. 103 p. 1988.

MARGESIN, R.; CIMADOM, J.; SCHINNER, F. Biological activity duringcomposting of sewage sludge at lowtemperatures. International Biodeterioration \& Biodegradation, vol. 57, p. 88-92. 2006.

NUNES, M.L. Appendino. Avaliação de procedimentos operacionais na compostagem de dejetos de suinos. Dissertação (Mestrado em Engenharia Ambiental) - Universidade Federal de Santa Catarina - UFSC. Florianópolis, 101f. 2003.

PEREIRA NETO, J.T. Manual de compostagem processo de baixo custo. Belo Horizonte: UNICEF. 56p. 1996.

PHILIPPI JUNIOR, A. Agenda 21 e resíduos sólidos. In: RESID'99 - SEMINÁRIO SOBRE RESÍDUOS SÓLIDOS,1999, Anais.... São Paulo: Associação Brasileira de Geologia de Engenharia, p. 15-26. 1999.

PIAZZA, E.T. Estudo e desenvolvimento de um sistema acelerado de compostagem e de fácil operação para pequenos espaços. Dissertação (Mestrado em Ciências Ambientais)- Universidade do Extremo Sul Catarinense - UNESC, 59f. Criciúma, 2004.

VIANA, E. Resíduos alimentícios do lixo domiciliar: caracterização, processamento e avaliação do uso como um ingrediente para ração de frangos de corte. Tese (Doutorado em Engenharia Civil)-Escola de Engenharia de São Carlos, Universidade de São Paulo, São Carlos,164 f. 1999.

ZHU, N. Effect of low initial C/N ratio on aerobic composting of swine manure with rice straw. Bioresource Technology, vol.98, p. 9-13. 2005.

Endereço para correspondência:

Eliane Spricigo Maragno

Rua Major Acácio Moreira, 239 apt $^{\circ} 503$

8880 I-I 60 Criciúma - SC - Brasil

Tel.: (48)3433-77 I 2

E-mail: elianemaragno@yahoo.com.br 